\title{
OS ESPAÇOS NAS INSTITUIÇÕES ESCOLARES: RASTROS DE CIDADES INVISÍVEIS
}

\author{
SPACES IN THE SCHOOL: TRACES OF INVISIBLE CITIES
}

\author{
Aline Rodrigues ${ }^{1}$ \\ http://lattes.cnpq.br/4979631040914423 \\ https://orcid.org/0000-0002-6516-4837 \\ Cláudia Inês Horn² \\ http://lattes.cnpq.br/8019717665577672 \\ https://orcid.org/0000-0002-1612-2067
}

Recebido em 23 de outubro de 2019

Aprovado em 18 de março de 2020.

\begin{abstract}
RESUMO: Este artigo busca refletir sobre os espaços pensados e organizados para as crianças ao longo da história nas instituições escolares, marcados por mecanismos de disciplinamento e controle. Problematiza os espaços institucionalizados que, por vezes, se constituem como paisagens comuns nas formas de ser, estar e movimentar-se. Propõe a possibilidade de pensar e potencializar outras movimentações nos espaços, a partir do conceito de linhas em Deleuze e também da obra Cidades Invisiveis, de Ítalo Calvino. É um artigo de abordagem teórica, que propõe reflexões a cerca das temáticas acima já descritas, por isso, foi realizada uma revisão de bibliografia e não uma aplicação prática.
\end{abstract}

Palavras-chave: Crianças. Escola. Organização dos espaços.

\begin{abstract}
This paper attempts to reflect on spaces that have been designed and organized for children in the school along history and marked by mechanisms of discipline and control. It problematizes institutionalized places that are sometimes constituted as common settings in the ways of being and moving. It proposes the possibility of thinking and potentializing other movements in those places considering the concept of lines as developed by Deleuze, and also Invisible Cities, by Italo Calvino. It is an article of theoretical approach, which proposes reflections about the above topics, so a review of the bibliography was done and not a practical application.
\end{abstract}

Keywords: Children. School. Space organization.

O presente artigo $^{3}$ tem como objetivo analisar os espaços voltados às crianças nas instituições escolares, marcados pelos seus mecanismos de disciplinamento e controle. Estes espaços foram especialmente pensados e projetados na Modernidade, e podem ser considerados como invenções eficientes de disciplinamento dos corpos e padronização de formas de ser, estar e se comportar. Nenhum espaço é neutro, mas carregado de forças que atravessam os sujeitos

\footnotetext{
${ }^{1}$ Mestre em Ensino e Doutoranda em Ensino pela Universidade do Vale do Taquari - Univates. E-mail: aliner@universo. univates.br

${ }^{2}$ Docente do Centro de Ciências Humanas e Sociais da Universidade do Vale do Taquari - UNIVATES. Pedagoga. Mestre e Doutora em Educação. E-mail: clauhorn@yahoo.com.br

${ }^{3}$ Este artigo é fruto das discussões realizadas na disciplina "Espaços e Organização da Educação Infantil”, do Curso de Pedagogia do Centro Universitário UNIVATES/Lajeado-RS-Brasil.
} 
que nele habitam. Pretendemos, trançar algumas linhas na esteira de Gilles Deleuze, a fim de problematizar alguns movimentos em torno dos espaços nas escolas, e também, a partir da leitura de um texto literário - "As Cidades Invisíveis” de Ítalo Calvino - provocando o nosso pensamento para pensar outros espaços possíveis nas escolas, potencializando movimentos, encontros e criações. Nosso propósito é poder pensar estas linhas pela via das sensações, dos desejos, criando possibilidades inventivas e escapes por onde potências singulares possam vazar. Nossa intenção também é levar ao estranhamento estes espaços normatizados, habitados por leis e regras, os quais, por vezes, constituem a grande maquinaria escolar.

\section{OS ESPAÇOS ESCOLARES: DISCIPLINAMENTO E CONTROLE}

Ainda hoje é possível perceber o quanto alguns ideais da Modernidade estão presentes nas instituições escolares. Recorremos aos escritos do filósofo Michel Foucault (2005), ao trazer a análise sobre os dispositivos de controle e vigilância e os mecanismos de punição existentes em algumas instituições, dentre elas destaca as prisões, os hospitais e as escolas, com seus tempos e espaços esquadrinhados, trazendo efeitos de um adestramento de corpos sociais. Conforme Foucault (2005), as escolas trabalham com mecanismos de controle e disciplinamento e os corpos que habitam essas instituições vão engendrando uma normalização (as possíveis ações em um determinado campo ou espaço que distingue o permitido e o proibido, o correto e o incorreto), pois devem seguir normas e regras, gerando um padrão de ser humano. A escola, instituição moderna e disciplinar por excelência, aciona, mesmo que sutilmente, mecanismos que comparam, diferenciam, hierarquizam, normalizam, excluem e homogeneízam os sujeitos atuantes no processo.

$\mathrm{Na}$ sociedade contemporânea, as crianças vivem em espaços e tempos geralmente definidos pelos adultos. Estes espaços e tempos possuem regras e sistemas de controle planejados e regulados também pelos adultos. Para além das escolas, também as praças, shoppings, parques de diversões, lojas, cinemas... enfim, os lugares que as crianças frequentam nas cidades, possuem suas formas de controle, seus modos de agir, suas possibilidades de exploração e de utilização definidos, bem como suas proibições e suas capturas. Percebemos que os espaços públicos destinados às crianças são locais que visam ao capitalismo, eles geralmente apresentam brinquedos prontos que valorizam a rapidez e a competição.

Corrêa (2011, p. 185) afirma que a "escola é uma instituição disciplinar. Isso implica em técnicas de coerção e esquadrinhamento do tempo, do espaço e dos movimentos de cada um”. Este esquadrinhamento visa à sujeição de forças, pensando em corpos dóceis e úteis para a sociedade, assim como indivíduos adestrados, o que contribui para um controle de cada um e da população. Santos (2009, p. 77) afirma que "o poder disciplinar tem como objeto a sujeição de corpo do indivíduo, tornando-o dócil e manipulável, mas não um corpo individual, e sim coletivo".

Aquino e Corazza (2009) contribuem para essa problematização, afirmando que a escola constitui-se de:

Conhecido espaço repleto de salas, horários e regras determinadas. Local em que todos os dias, faça chuva ou sol, exceto no sábado e no domingo, eles chegam, trazendo suas mochilas, tênis e boné. Ingressam com mais ou menos sono, com mais ou menos pressa, com mais ou menos vontade de começar... novamente, pois a jornada escolar acaba, justamente, para ser reiniciada no dia seguinte. Há sempre uma pausa entre um turno e outro. Se, por um lado, ela dura oito 
horas, por outro, estende-se entre março e dezembro. Dia após dia, ano após ano. Uma vez que as explicações, os exercícios, as perguntas, as aulas de laboratório, as entrevistas com os pais, bem como as pautas das inúmeras reuniões de professores para tratar da aprendizagem dos alunos, nunca se esgotam (AQUINO e CORAZZA, 2009, p. 106).

Também podemos destacar aqui as contribuições de Veiga-Neto (2005, p. 84), ao afirmar que "a escola encarregou-se de operar as individualizações disciplinares, engendrando novas subjetividades e, com isso, cumpriu um papel decisivo na constituição da sociedade moderna". A escola foi concebida como uma máquina capaz de transformar os corpos num objeto do poder disciplinar e assim, "torná-los dóceis; [...] a escola é, depois da família (mas, muitas vezes, antes dessa), a instituição de sequestro pela qual todos passam (ou deveriam passar...) o maior tempo de suas vidas, no período da infância e da juventude" (VEIGANETO, 2005, p. 84 - 85).

Para o referido autor, a escola foi a instituição moderna mais poderosa na articulação entre o poder e o saber, "de modo a fazer dos saberes a correia (ao mesmo tempo) transmissora e legitimadora dos poderes que estão ativos nas sociedades modernas" (VEIGA-NETO, 2005, p. 139). Operam na escola complexos dispositivos disciplinares que, gradualmente disseminam sua produtividade por todo o corpo social e "desenvolverão estratégias cada vez mais sofisticadas que irão levando sua forma de exercer o poder muito além dos seus próprios muros" (KOHAN, 2005, p. 91).

Refletindo especialmente sobre os espaços da sala de aula, Kohan (2005), inspirado nas teorizações foucaultianas, faz uma comparação do papel do professor com o pastor e afirma que o pastor exerce seu poder sobre seu rebanho, agrega, guia e conduz, e a relação entre pastor e rebanho é uma relação de dependência absoluta, tanto individual quanto grupal. O autor completa sua ideia dizendo que o pastor necessita, para cuidar do seu rebanho, conhecer cada um dos seus membros. É a partir do professor que toda disciplina é estabelecida, ele ocupa um espaço estratégico nas relações de poder, controle e regramento, pois sem o professor, os alunos "não saberiam o que fazer, como aprender, de que maneira comportar-se; eles não saberiam o que está bem e o que está mal” (KOHAN, 2005, p. 88).

Nas escolas, os indivíduos não fazem qualquer coisa, em qualquer momento, em qualquer lugar. Os espaços são cuidadosamente delimitados, o tempo é marcado por um cronograma preciso, regular e regulado, os aprendizados são organizados em etapas, de forma tal a exercitar em cada período, um tipo de habilidade específica. Um conjunto de formas reguladas de comunicação e um conjunto de práticas de poder conformam o campo do que é possível perceber, dizer, julgar, pensar e fazer na instituição escolar (KOHAN, 2005, p. 79).

É a partir desse panorama que podemos questionar: que efeitos a organização dos espaços produz nos sujeitos que frequentam obrigatoriamente a escola, por no mínimo, nove anos (sem contar o tempo de Educação Infantil e Ensino Médio)? O que estamos fazendo de nós mesmos, ocupando os espaços escolares?

O aluno, ao ser capturado por uma rede de normas e leis pedagógicas, torna-se objeto e alvo com base no qual e sobre o qual deverá ser implementada a organização da vida escolar. Assim, as divisões operadas pelo regimento escolar permitem que o sujeito pedagógico seja colocado em segmentos lineares (AQUINO e CORAZZA, 2009, p. 156 e 157). Falando em vida escolar, os mesmos autores dizem que vale lembrar a existência de uma rotina linear que 
é inegável: o primeiro, o segundo, o terceiro trimestre... Os alunos aprovados, em recuperação e os reprovados... e, assim por diante. A jornada escolar é composta por repetições, que não estão ocultas, mas disfarçam-se dentro do ambiente escolar.

Nas escolas, os indivíduos não fazem qualquer coisa, em qualquer momento e lugar. Os espaços são cuidadosamente delimitados, o tempo é marcado por um cronograma preciso, regular e regulado, os aprendizados são organizados em etapas, de forma tal a exercitar em cada período, um tipo de habilidade específica. Um conjunto de formas reguladas de comunicação e um conjunto de práticas de poder conformam o campo do que é possível perceber, dizer, julgar, pensar e fazer na instituição escolar (KOHAN, 2005).

Os espaços escolares foram historicamente pensados por adultos e hoje estão configurados numa lógica neoliberal, buscando individualidade, liberdade, competição. As crianças são inseridas na escola mediante determinadas regras e normas. Regras que por vezes se repetem de escola para escola, que são fixas, tal como aponta Calvino, ao falar da cidade de Aglaura:

Não saberia dizer nada a respeito de Aglaura além das coisas que os próprios habitantes da cidade sempre repetem: uma série de virtudes proverbiais, de defeitos igualmente proverbiais, algumas extravagâncias, algumas inflexíveis observâncias às regras (CALVINO, 2008, p. 65).

Tudo sempre lá, tudo tão igual. O que estas repetições tem de relação com a escola? À disciplina rígida e firme parece que hoje já se tem uma flexibilidade maior. No entanto, não podemos esquecer que hoje operamos com o controle das sociedades, o controle dos corpos. Um controle que parece não ter um lugar fixo, mas que se espraia aos quatro ventos e por este espraiamento se torna perigoso, passivo de atenção. Um controle que parece não estar em lugar algum, mas que de fato está em todos os lugares. Pela disciplina, uma marcação de lugar, pelo controle, uma sutileza nos movimentos, na conduta, na vigilância dos cidadãos.

Um controle que se espraia, por vezes tão sutil que se passa desapercebido. Nas instituições escolares já não são mais os "superiores" que controlam, mas um sujeito vigia o outro. A avaliação e todo o seu conjunto de registro e anotações também englobam instrumentos uteis para uma sociedade de controle. Os instrumentos tecnológicos também estão nas escolas, por vezes em espaços imperceptíveis, mas estão lá cumprindo suas utilidades, registrando todas as ações dos sujeitos. Talvez podemos dizer que na escola temos uma ilusão de que ultrapas samos o tempo da disciplina.

Uma possível marca dessas práticas individualizantes e compartimentadas é a "atribuição ao sujeito escolar de uma suposta autonomia e responsabilidade no exercício de seus direitos e deveres escolares" (AQUINO e CORAZZA, 2009, p. 157 e 158). O aluno pode realizar escolhas com 'liberdade' e 'autonomia', desde que essa liberdade espelha o que é permitido e proibido nos diversos dispositivos de controle. Tudo isso "permite à máquina escolar um refinamento do exercício de controle sobre os sujeitos escolares, já que estes se tornam sujeitos governáveis, no âmbito coletivo, e autogovernados, no âmbito individual" (AQUINO e CORAZZA, 2009, p. 157 e 158).

Percebemos que as práticas pedagógicas, com o passar dos anos, sustentam-se enclausuradas, pois ainda buscam classificar os alunos em normais e anormais, tentando, sempre que possível, homogeneizá-los, passando as mesmas atividades e conteúdos que devem ser compreendidos por todos num mesmo espaço e tempo. É possível pensar em outros territórios? Parafraseando Gallo e Aspis (2011, p. 174), quando dizem: "Escola instituição das crianças. 
Escola-condução. Escola-controle. Conduzir as crianças" e mais "Escola: polícia das crianças. Polícia do material, polícia do virtual. Enquanto confinada à instituição, é fácil fugir da escola: basta pular o muro". É possível pensar numa Escola-encontro? Escola-desejo? Escola-imprevisível? Escola-vida? ... sem desejar pular o muro, pois algo impulsiona a habitar aquele lugar?

\section{POSSIBILIDADES PARA ESCAPAR ...AS CIDADES INVISÍVEIS}

A partir destes estudos, buscamos garimpar por brechas e fissuras em meio aos mecanismos de disciplinamento e controle dos espaços escolares, e nos deparamos com a obra "As Cidades Invisíveis”, onde Ítalo Calvino, através dos personagens denominados Kublai Khan e Marco Polo, conta algumas viagens imaginárias para diferentes cidades. A obra provocou o nosso pensamento, pois, quando o autor fala das cidades, nossa memória nos reportava aos espaços escolares, como no excerto que segue:

Inutilmente, magnânimo Kublai, tentarei descrever a cidade de Zaíra dos altos bastiões. Poderia falar de quantos degraus são feitas as ruas em forma de escada, da circunferência dos arcos dos pórticos, de quais lâminas de zinco são recobertos os tetos; mas sei que seria o mesmo que não dizer nada. A cidade não é feita disso, mas das relações entre as medidas de seu espaço e os acontecimentos do passado: a distância do solo até o lampião e os pés pendentes de um usurpador enforcado [...]. A cidade se embele como uma esponja dessa onda que reflui das recordações e se dilata. Uma descrição de Zaíra como é atualmente deveria conter todo o passado de Zaíra. Mas a cidade não conta o seu passado, ela o contém como as linhas da mão, escrito nos ângulos das ruas, nas grades das janelas, nos corrimãos das escadas, nas antenas dos para-raios, nos mastros das bandeiras, cada segmento riscado por arranhões, serradelas, entalhes, esfoladuras (CALVINO, 2008, p. 14-15).

Da mesma forma como Calvino retrata a cidade, relatando sobre suas ruas, suas casas e escadas, problematizamos a escola também em sua arquitetura, em seus espaços: corredores contendo a indicação "Não corra"; portas com partes em vidro, que parecem remeter à uma vigilância; salas de aula uniformes, classes, quadro, mesa do professor e armário, espaço que parece falar "Silêncio, aqui só tem lugar para os conhecimentos descritos nos Planos de Estudos". Mas a escola "não é feita disso, mas das relações entre as medidas de seu espaço e os acontecimentos” (CALVINO, 2008, p. 14). Pelos espaços comuns e naturalizados, há que se passar outras coisas; há que nos tocar de outras formas para além daquelas institucionalizadas. Acreditamos que a escola "se embebe como uma esponja dessa onda que reflui das recordações e se dilata” (CALVINO, 2008, p. 14).

Dilatações ...linhas de fuga? Buscamos com o filósofo Gilles Deleuze (1998) algumas pistas para pensar sobre os movimentos que ocorrem na escola e alguns rastros por onde podemos "escapar" destes espaços escolares permeados de disciplina e controle.

Deleuze nos traz três conceitos de linhas, as quais queremos aqui brevemente abordar e tensionar com a problemática central deste artigo. Uma delas são chamadas de linhas duras, as quais estão ligadas aos binarismos, às noções fixas, às fases delimitadas e às identidades permanentes. Podemos pensar os espaços escolares como estas linhas. Elas também podem ser denominadas de molares, as quais demarcam territórios disciplinares e engendram o controle. Quando estas linhas estão fortemente marcadas, existe o perigo da cristalização dos saberes e dos espaços, a resistência à toda diferença, pensando através de formas únicas e de 
verdades instaladas, emitindo juízo de valor, definindo o que é bom ou ruim, o que é certo ou errado, quem está "dentro" ou "fora" do processo. Percebe-se esta linha em Anastácia, cidade descrita por Calvino (2008, p. 16) como uma

cidade enganosa, tem um poder, que às vezes se diz maligno e outras vezes benigno: se você trabalha oito horas por dia como minerador de ágatas ônix crisóprasos, a fadiga que dá forma aos seus desejos toma dos desejos a sua forma, e você acha que está se divertindo em Anastácia quando não passa de seu escravo.

Em meio a estas linhas territorializadas, algumas brechas ou algumas fissuras são criadas pelas próprias crianças, na intenção de modificar estes espaços que a elas são destinados, a fim de pluralizar as vias já postas, inventando outras possibilidades para as já dadas. Estas linhas são denominadas de linhas flexíveis, ou molares, as quais permitem que o fixo sofra algumas pequenas e sutis rachaduras. Estes movimentos são quase imperceptíveis e as mudanças que eles provocam são pequenas.

A terceira linha - mas nem por isso menos importante, lembrando que todas elas se movimentam, sendo umas dependentes das outras, se misturando, se alternando, coexistindo - é chamada de fuga, as quais são responsáveis por causar rupturas bem marcantes, modificando o território anterior.

Há linhas que não se reduzem ao trajeto de um ponto, e escapam da estrutura, linhas de fuga, devires, sem futuro nem passado, sem memória, que resistem à máquina binária, devir-mulher que não é nem homem nem mulher, devir-animal que não é nem bicho nem homem. (DELEUZE, 1998, p. 36)

Estas linhas também podem ser denominadas de linha de criação. Deleuze nos diz que elas também podem ser perigosas, justamente por esta mudança radical que provocam, uma vez que as linhas de fuga "saltam de uma linha a outra, entre seres totalmente heterogêneos; fissuras, rupturas imperceptíveis, que quebram as linhas mesmo que elas retomem noutra parte" (DELEUZE, 1998, p. 36).

Pensar os espaços escolares pelos movimentos que essas três linhas nos sugerem, talvez seja uma potência para borrar o controle que hoje encontramos nas instituições escolares. Estas linhas nos permitem problematizar e criar possibilidades inventivas para que os corpos infantis possam passar por cruzamentos e serem pensados de outros modos.

Calvino (2008) ajuda a traçar alguns fios em torno das relações. Em meio às linhas duras, as relações, como possibilidades de fazer vazar as subjetividades e os desejos de cada sujeito, sem preocupação com a forma ou a linearidade que deve seguir, mas tentando criar rizomas conectados com a vida em meio a este lugar que esmaga. Calvino (2008, p. 36 - 37) afirma que

é inútil determinar se Zenóbia deva ser classificada entre as cidades felizes ou infelizes. Não faz sentido dividir as cidades nessas duas categorias, mas em outras duas: aquelas que continuam ao longo dos anos e das mutações a dar forma aos desejos e aquelas em que os desejos conseguem cancelar a cidade ou são por esta cancelados.

E aqui acrescentamos: não devemos tentar classificar as escolas como boas ou ruins, indicando defeitos e qualidades, mas talvez pensar como cada criança pode, em meio ao espaço 
institucionalizado em que está inserida, pensar em linhas de criação, de invenção, que potencialize seus desejos, da mesma forma como os professores que habitam estes espaços. Tal como a cidade de Marósia, descrita por Calvino (2008, p. 141), que

quando menos se espera se vislumbra uma cidade diferente, que desaparece um instante depois. Talvez toda a questão seja saber quais palavras pronunciar, quais gestos executar, e em que ordem e ritmo, ou então basta o olhar a resposta o aceno de alguém, basta que alguém faça alguma coisa pelo simples prazer de fazê-la, e para que o seu prazer se torne um prazer para os outros; naquele momento todos os espaços se alteram, as alturas, as distâncias, a cidade se transfigura, torna-se cristalina, transparente como uma libélula.

Transfigurar. Desaparecer instantes depois. Metamorfosear. Talvez estas sejam tentativas que possam estar presentes nas instituições escolares, em meio aos corpos que lá habitam, experimentando, entre as linhas moleculares, molares e de fuga algumas brechas para fazer vazar as subjetividades e os desejos de cada sujeito, potencializando experimentações outras, criações outras. Para Calvino (2008, p.16),

quem se encontra uma manhã no centro de Anastácia será circundado por desejos que se despertam simultaneamente. A cidade aparece como um todo no qual nenhum desejo é desperdiçado e do qual você faz parte, e, uma vez que aqui se goza tudo o que não se goza em outros lugares, não resta nada além de residir nesse desejo e se satisfazer.

Assim, estabelecemos um desafio para as cidades e as escolas: pensar seus espaços com as crianças, a partir de suas perspectivas. Territórios não escolarizantes, talvez não tão institucionalizados, mas abertos ao encontro, ao acaso, às formas inusitadas da vida. Espaços que não compartimentalizam faixas etárias, que não segregam modos de se movimentar, e não fragmentam o tempo em períodos, em sinetas, em classes, que geralmente é o tempo da aula. Escola-encontro. Escola-desejo. Escola-imprevisível. Escola-vida. ... sem desejar pular o muro, pois algo impulsiona a habitar esse lugar. Optamos por finalizar o texto - mas não as provocações em nosso pensamento - com as indicações que Marco Polo oferece à Kublai Khan - ambos personagens de Ítalo Calvino em "As cidades invisíveis", para não sofrer nos espaços nos quais habitamos. Preferimos arriscar-nos!

O inferno dos vivos não é algo que será; se existe, é aquele que já está aqui, o inferno no qual vivemos todos os dias, que formamos estando juntos. Existem duas maneiras de não sofrer. A primeira é fácil para a maioria das pessoas: aceitar o inferno e tornar-se parte deste até o ponto de deixar de percebê-lo. A segunda é arriscada e exige atenção a aprendizagem contínua: tentar saber reconhecer quem e o que, no meio do inferno, não é inferno, e preservá-lo, e abrir espaço (CALVINO, 2008, p. 150).

\section{REFERÊNCIAS}

AQUINO, Júlio Groppa; CORAZZA, Sandra. (2009). Abecedário: Educação da diferença. Campinas: Papirus.

CALVINO, Ítalo. (2008). As cidades invisíveis. São Paulo: Companhia das Letras. CORRÊE, Guilherme C. \& PREVE, Ana Maria H. A educação e a maquinaria escolar: 
produção de subjetividade, biopolítica e fugas. Sorocaba, SP, REU: v. 37, n.2, p 181-202, dez 2011.

DELEUZE, Gilles. (1998) Diálogos. São Paulo: Escuta.

FOUCAULT, Michel. (2005). Vigiar e Punir: nascimento da prisão. Petrópolis: Vozes.

GALLO, Silvio e Aspis, R. L. (2011) Biopolítica-vírus e educação-governamentalidade e escapar e... Sorocaba, SP: REU.

KOHAN, Walter. O. (2005) Infância. Entre educação e filosofia. Belo Horizonte, MG: Autêntica.

SANTOS, Iolanda Montano dos. Um corpo mais perfeito. In: LOPES, Maura Corcini; HATTGE, Morgana Domênica (Org.). Inclusão escolar: conjunto de práticas que governam. Belo Horizonte: Autêntica Editora, 2009.

VEIGA-NETO, Alfredo. (2005). Foucault \& a Educação. Belo Horizonte: Autêntica. 